\title{
Volume 1 Author Index
}

\begin{tabular}{|c|c|c|c|}
\hline Achadiyani & 432,369 & Hidayat B & 252 \\
\hline Adhika OA & 126 & Hidayat M & $200,341,470,583$ \\
\hline Afiati & 1 & Hutomo F & 252 \\
\hline Agustina $\mathrm{H}$ & 48,224 & Imelda & 575 \\
\hline Alif M & 20 & Imron A & 28 \\
\hline Amelia M & 409 & Irawan VR & 477 \\
\hline Angwarmase A & 470 & Ivone $\mathrm{J}$ & 558 \\
\hline Anisa IN & 187 & Jahja DS & 499 \\
\hline Anwar R & 20,18 & Jasaputra DK & 409 \\
\hline Apreza RT & 583 & Jeffrey & 296 \\
\hline Aribowo T & 549 & Jonathan R & 61 \\
\hline Astarto NW & 69 & Khiong K & 319 \\
\hline Azaria & 305 & Kresnoadi E & 525 \\
\hline Azaria C & 432,575 & Krisna DM & 525 \\
\hline Budiawan H & 252 & Kristiana R & 224 \\
\hline Budiman & 533 & Kurniadi MW & 200 \\
\hline Bulan IAKT & 517 & Ladi JE & 445 \\
\hline Chikita V & 341 & Lasminingrum L & 143 \\
\hline Christiany S & 200 & Liana LK & 241 \\
\hline Clara S44 & 5 & Limyati Y & $445,499,568$ \\
\hline Damayanti BS & 1 & Lismayanti L & 486 \\
\hline Damayanti NA & 187 & Lucianus J & 558 \\
\hline Dewi YA & 143 & Lucretia T & 369,575 \\
\hline Dillon D & 533 & Mahdiani S & 143 \\
\hline Djuwantono $\mathrm{T}$ & 69 & Mardiyanto FYD & 499 \\
\hline Eunike E & 540 & Marito DR & 319 \\
\hline Evacuasiany E & $12,41,241$ & Masjhur JS & 252 \\
\hline Fahdiansyah & 180 & Masria S & 369 \\
\hline Fanty F & 417 & Maulana A & 525 \\
\hline Farenia R & 432 & Mercya Y & 417 \\
\hline Fen Tih & $12,76,214$ & Mulyanto ID & 252 \\
\hline Garna DR & 558 & Mustamu HL & 241 \\
\hline Gunadi JW & 445 & Novita N & 48 \\
\hline Gunanegara RF & 456 & Nugraha RA & 382 \\
\hline Gunawan D & 568 & Nurazizah E & 76 \\
\hline Hadinata S & 233 & Onggowidjaja P & 97 \\
\hline Hasianna ST & 85 & Paskaria C & 170 \\
\hline Hassan AH & $1,48,113$ & Permadi AR & 351 \\
\hline Hendarin A & 394 & Permana RJ & 305 \\
\hline Herawati H & 156 & Prahastuti S & 200,341 \\
\hline Herdiman H & 233 & Pramono H & 382 \\
\hline Hernowo BS & $1,48,113,224$ & Prawira A & 85 \\
\hline Herryadi N & 358 & Pribadi A & 20 \\
\hline
\end{tabular}




$\begin{array}{llll}\text { Purba BM } & 583 & \text { Susanto D } & 477 \\ \text { Purwanto B } & 143 & \text { Susilo W } & 568 \\ \text { Puspasari G } & 533 & \text { Suwindere W } & 76 \\ \text { Rachmawati SF } & 341 & \text { Tanuwijaya F } & 233 \\ \text { Ratnawati H } & 351,517 & \text { Tanzilah S } & 358 \\ \text { Ridwan AJ } & 113 & \text { Tih F } & 470 \\ \text { Rosnaeni } & 305 & \text { Tiono H } & 326 \\ \text { Ruhimat U } & 394 & \text { Tjahjani S } & 319 \\ \text { Rusman AA } & 358 & \text { Tjokropranoto R } & 409 \\ \text { Rusmana D } & 41 & \text { Utami RD } & 156 \\ \text { Safitri D } & 341 & \text { Vera } & 91 \\ \text { Sanjaya A } & 61 & \text { Wahid MH } & 456 \\ \text { Sapta MI } & 500 & \text { Wahyudianingsih R } & 382 \\ \text { Shahib MN } & 97 & \text { Wardani KRP } & 583 \\ \text { Sinaga HM } & 445 & \text { Wargasetia TL } & 277,351,500,517 \\ \text { Sitha C } & 91 & \text { Wiardi R } & 264 \\ \text { Soemardji AA } & 187,341,417 & \text { Widarda IR } & 264 \\ \text { Soeng S } & 85 & \text { Widhiatmo AO } & 258 \\ \text { Soewoto W } & 549 & \text { Widyahening IS } & 456 \\ \text { Subroto H } & 486 & \text { Wiharja A } & 287 \\ \text { Sugiarto C } & 61 & \text { Wiriadisastra K } & 28 \\ \text { Suhendra A } & 105 & \text { Wirjomartani BA } & 258 \\ \text { Sukma N } & 156 & \text { Wisudarma Y } & 224 \\ \text { Sulaiman E } & 143 & \text { Yellianty } & 69 \\ \text { Suprapto AK } & 12 & \text { Yudistiro R } & 252 \\ \text { Suryadi C } & 41 & \text { Yudoyono F } & 258 \\ \text { Suryanti S } & 113 & & \end{array}$

